\title{
Comparison of automated breast volume scanning to hand-held ultrasound and mammography
}

\section{Confronto tra scansione ecografica automatica del volume mammario, ecografia convenzionale e mammografia}

\author{
Zhi Li Wang • Jian Hong Xu • Jun Lai Li • Yan Huang • Jie Tang \\ Department of Ultrasound, Chinese People's Liberation Army General Hospital, 28 Fuxing Road, Beijing 100853, \\ People's Republic of China \\ Correspondence to: Zhi Li Wang, Tel.: +86-10-66936848, Fax: +86-10-68161218, e-mail: wzllg@ sina.com
}

Received: 21 August 2011 / Accepted: 11 October 2011 / Published online: 27 July 2012

(C) Springer-Verlag 2012

Erratum to: La radiol med

DOI 10.1007/s11547-012-0836-4

The original version of this article, unfortunately, contained a mistake. The name of the second author should have been Jian Hong Xu instead of Jian Hong Xw. 